\title{
DRUG-INDUCED CILIARY BODY OEDEMA: A NEW THEORY
}

\author{
PETER H. KRIEG and ISAAC SCHIPPER \\ Lucerne, Switzerland
}

\begin{abstract}
SUMMARY
Drug-induced oedema of the ciliary body is rare, and occurs predominantly following exposure to sulphonamides. In a 31-year-old patient in her 37th week of pregnancy, we observed reversible myopia of -4.75 dioptres following the ingestion of chlorthalidone. In a second case report we describe, in a 61-year-old patient suffering from aspirin-sensitive asthma, recurrent ciliary body oedema with a marked spastic component which was triggered by the medications acetazolamide, dipivefrine and pilocarpine. We explain oedema of the ciliary body on the basis of the eicosanoids. We believe that the oedema is caused mainly by prostaglandins and that leucotrienes are predominantly responsible for the spastic component. We postulate a drug-induced elevation in eicosanoid concentrations, as well as certain interrelationships between ciliary body oedema and aspirin-sensitive asthma.
\end{abstract}

Drug-induced ciliary body oedema, with transient myopia as its cardinal symptom, occurs only rarely. However, the phenomenon has been recognised for many years, and numerous case reports describing it exist in the literature.

In most of the reports, the disorder occurred following the ingestion of sulphonamides (mainly sulphonamides possessing long half-lives and with diuretic action): chlorthalidone, ${ }^{1,2}$ sulphanilamide, ${ }^{3}$ indapamide $;^{4}$ acetazolamide $;^{5-7}$ the chemotherapeutic, sulphonamide sulphamethoxazole $;{ }^{8}$ glibenclamide, ${ }^{9}$ which is an anti-diabetic sulphonamide derived from sulphonylurea; promethazine, ${ }^{10}$ the aldosterone antagonist spironolactone: ${ }^{11}$ the synthetic hormone tetracasactrin $(\mathrm{ACTH}) ;{ }^{12}$ isosorbide dinitrate,${ }^{13}$ the prolactin antagonist bromocriptine, ${ }^{14}$ and a variety of other drugs such as tetracycline, ${ }^{15}$ penicillamine, ${ }^{16}$ quinine, ${ }^{17}$ metronidazole,${ }^{18}$ isotretinoin $^{19}$ and aspirin. ${ }^{20}$

From: Ophthalmology Clinic, Cantonal Hospital, Lucerne, Switzerland.

Correspondence to: P. Krieg, MD, Dorfstrasse 94, CH-8706 Meilen, Switzerland.
The clinical picture is generally uniform. Symptoms usually appear 1-2 days following ingestion of the drug and last for 2-8 days after the medication has been withdrawn. The degree of myopia ranges from $-0.75^{4}$ to -8 dioptres. ${ }^{6}$ The patients are predominantly young women, and the myopia occurs particularly frequently during pregnancy. ${ }^{1,6,21}$ In addition to myopia, the anterior chamber may become markedly shallower, a change which is associated with the risk of acute (angle-closure) glaucoma. ${ }^{7,8,15,20,22}$ Furthermore, oedema of the retina has often been observed, most commonly with central, radial folds. ${ }^{1,6,8,20-23}$ Choroidal detachment has also been described. ${ }^{7}$

Most authors have assumed that ciliary body oedema was responsible for such observations. Due to relaxation of the zonules, the oedema would lead to a thickening of the lens as well as to the displacement of the iris-lens diaphragm. ${ }^{6,8,10,23}$ In any case, convincing explanations for the aetiology of oedema of the ciliary body are lacking. We present here a new theory to account for ciliary body oedema, with and without a spastic component. Our theory is based upon an imbalance in prostaglandin-thromboxane-leucotriene metabolism.

\section{CASE REPORTS}

Case 1

A 31-year-old patient who had suffered in her youth from asthma was prescribed a sulphonamide diuretic (chlorthalidone) for moderate oedema of the lower leg during her 37 th week of pregnancy. The oedema responded favourably to the first tablet, so that the patient did not take a second tablet until 5 days later, by which time the oedema had worsened. Approximately 6 hours later, after awakening from a mid-day nap, she experienced bilateral deterioration of her distance vision and consulted our emergency ward.

In this patient, whose ophthalmological anamnesis was uneventful and who did not wear spectacles, we found an uncorrected visual acuity of counting 
fingers at $2 \mathrm{~m}$; corrected visual acuity with a refraction of -4.25 dioptres bilaterally was 20/20. Intraocular pressure was $21 \mathrm{mmHg}$ in the right eye, and $18 \mathrm{mmHg}$ in the left eye. The light reflex and the depth of the anterior chamber were normal. Central radial folds with fading of the foveal reflex could be observed on the fundus. Diabetogenic metabolism was excluded. Three days later, during her second visit, we found a further worsening of the myopia, to -5 dioptres in the right eye and -4.75 dioptres in the left; visual acuity was unchanged. Slit lamp examination revealed irritation of the anterior chamber, with evidence of a moderate presence of cells.

Treatment with 2 drops of the cycloplegic agent cyclopentolate led to a significant improvement in the myopia within 1 day: to -1.25 dioptres and -1.0 dioptres, right and left eyes, respectively. During the final clinical examination 3 days later ( 7 days following the onset of the symptoms) the patient had no complaints, with the exception of mild soreness of the eyes which occurred while performing close work. The right eye still presented a refraction of -0.5 dioptres, while the left eye had become emmetropic. As determined echographically, the anterior chambers had deepened by 0.57 $\mathrm{mm}$ (right) and $0.52 \mathrm{~mm}$ (left) compared with the first examination, that is, within 7 days. The diameters of the right and left lenses had decreased by $0.2 \mathrm{~mm}$ and $0.14 \mathrm{~mm}$, respectively.

\section{Case 2}

A 61-year-old patient was admitted to our clinic in March 1991 for an operation on presenile cataract of the left eye. His medical history included a myocardial infarction at the age of 29 years, and he suffered from aspirin-sensitive asthma as well as (from the age of 45 years) from gout. Bilateral ocular hypertension with pressures up to $24 \mathrm{mmHg}$ OD and $22 \mathrm{mmHg}$ OS had been diagnosed 1 year previously. The cataract operation in the left eye (phacoemulsification; intraocular implantation of a silicon lens, model AM0 SI/19 NB) was performed on 14 March 1991.

Due to a pronounced post-operative increase in intraocular pressure to $50 \mathrm{mmHg}$, it was necessary to administer high oral and intravenous doses of acetazolamide during the first 36 hours following the operation, to a total dose of $1.75 \mathrm{~g}$. Although this treatment led to the normalisation of the intraocular pressure, the patient subsequently complained of sharp, cramp-like pain in the region of the left eye. In consideration of his recognised aspirin intolerance, the patient was prescribed the analgesic acetaminophen. Under this medication his complaints became less severe but did not disappear entirely. Visual acuity improved from 20/80 to 20/20.

Following discharge from the hospital, the patient mistakenly took an aspirin derivative (mefenamic acid) for incessant pain. The result was the development of nocturnal dyspnoea and cough, becoming increasingly refractory to therapy. Ultimately, in September 1991, the patient was referred to a highaltitude clinic, where the diagnosis of non-atopic bronchial asthma with suspected aspirin intolerance, along with chronic bilateral sinusitis maxillaris, was made. The precipitating agent was declared to be the non-steroidal anti-rheumatic medication, mafenamic acid.

The cataract operation on the right eye was performed in our clinic on 5 December 1991 (phacoemulsification; posterior chamber lens implantation, AMO SI 26 NB). As previously, an elevation in intraocular pressure in the right eye to $34 \mathrm{mmHg}$, unaccompanied by pain, occurred on the first postoperative day. Pressure normalised following a single oral dose of acetazolamide $250 \mathrm{mg}$. Visual acuity improved from $20 / 80$ to $20 / 20$.

Three weeks post-operatively, the pressure in the right eye had once again increased, this time to 38 $\mathrm{mmHg}$. Therapy to reduce intraocular pressure (oral acetazolamide and locally applied $2 \%$ pilocarpine) was administered as a temporary measure.

We did not see the patient again until 11 May 1992, when he came with the complaint of blurring of vision in both eyes. Posterior capsular opacification was diagnosed; the intraocular pressure measured 40 $\mathrm{mmHg}$ OD and $22 \mathrm{mmHg}$ OS. This, together with an increase in the cup/disc ratio and arcuate scotomata in the visual field, made the diagnosis of glaucoma clear. There was no pressure reduction with betaxolol eye drops but also no initiation of asthma. One day after administration of dipivefrine $0.1 \%$, extremely sharp peribulbar pain accompanied by photophobia occurred. On slit lamp examination the right eye looked completely normal, and the intraocular pressure measured $22 \mathrm{mmHg}$.

After reduction of the pain and of the intraocular pressure through acetazolamide administration, a second trial with dipivefrine was attempted, but sharp pain recurred. This time conjunctival injection, flattening of the anterior chamber, mild flare with some cells in the anterior chamber, and miosis could be observed.

Dipivefrine was withdrawn, and therapy with pilocarpine was initiated. The pressure measured 15 $\mathrm{mmHg}$ OD, but an unbearable pain in the region of the right eye occurred. Massive cellular reaction of the flattened anterior chamber, miosis, and marked narrowing of the anterior chamber could be observed. After cessation of pilocarpine therapy and initiation of local therapy with prednisolone acetate, the irritation in the anterior chamber lessened considerably. Pain was not relieved by cyclopentolate but was markedly reduced after administration of atropine drops $2 \%$. 
In August 1992, because of a rise in intraocular pressure to $42 \mathrm{mmHg}$, thermal sclerostomy and local mitomycin application were performed. After an initial reduction, pressure rose again and in December 1992 a double-plate Molteno device was implanted. The pressure was normalised, but 1 month later a circular choroidal detachment with severe pain occurred and responded well to systemic corticosteroids. Since then the right eye has been quiet and the pressure normal, but the patient still complains of slight pain.

\section{DISCUSSION}

The transient myopia following the ingestion of chlorthalidone that is described in the first case report is similar to that in a number of previously reported cases which occurred following the ingestion of a sulphonamide preparation..$^{1,2,5,21} \mathrm{We}$ also believe that the aetiology in our patient is to be traced to oedema of the ciliary body, resulting in relaxation of the zonules and in turn leading to a thickening of the lens (proven echographically) and an associated increase in the refractive index. Similarly, a displacement of the iris-lens diaphragm occurred, with the anterior chamber becoming slightly shallower.

It has not as yet been possible to elucidate the cause of oedema of the ciliary body. Some authors suspect an underlying allergic basis. ${ }^{822}$ This theory must be rejected, however, since re-exposure to the same medication has proved uneventful. ${ }^{1,10} \mathrm{We}$ believe that ciliary body oedema is related to the eicosanoids (a general term for prostaglandins, thromboxane and leucotrienes). Prostaglandins are recognised to be mediators of inflammation and cause vasodilation with increased permeability. ${ }^{24}$ In the eye, this can cause breakdown of the bloodaqueous barrier, and oedema of the macula. ${ }^{25,26}$ Furthermore, prostaglandins cause miosis ${ }^{27}$ and exert a hypotensive effect following an initial rise in intraocular pressure. ${ }^{28}$ Thus, oedema of the ciliary body, like that of the macula, can be fully explained on the basis of the actions of prostaglandins.

Drugs belonging to the sulphonamide-diuretic group stimulate the synthesis of prostaglandin $E_{2}$. To date this has been established for frusemide, ${ }^{29}$ indapamide ${ }^{30}$ and bendrofluazide. ${ }^{31}$ There are indications that the same is true of acetazolamide, ${ }^{32}$ since following inhalation this substance, like frusemide, exerts a bronchodilatory effect, which can be explained on the basis of the synthesis of the bronchodilator, prostaglandin $\mathrm{E}_{2}$.

As in our first case report, the literature reports numerous descriptions of oedema of the ciliary body during pregnancy (see above). This higher prevalence in pregnant women can be explained on the basis of the fact that levels of prostaglandins (especially that of prostacyclin, $\mathrm{PGI}_{2}$ ) are already elevated during pregnancy. ${ }^{33}$ Further pharmacological stimulation would suffice to precipitate oedema of the ciliary body and also possibly of the macula.

A further unique characteristic of the prostaglandins relates to their capability (due to their vasodilatory properties) of potentiating the oedemainducing effects of histamine and bradykinin..$^{34,35}$ Furthermore, in the anterior uvea, a significant increase in vascular permeability also occurs. ${ }^{36}$ This may explain why the ciliary body is the only tissue in which oedema is manifested following the intake of drugs of this type. Since drug-induced oedema of the ciliary body occurs very rarely, there must be numerous factors contributing to the local accumulation of prostaglandins, such as an inborn error in eicosanoid metabolism or a clinical or sub-clinical infection which is associated with elevated prostaglandin concentrations. The precipitating drugs, particularly sulphonamides, are commonly taken to treat infections. We also know that certain of these substances have an additional effect, namely the stimulation of histamine release. In particular this is true for the amide group of drugs, including sulphonamides, the amidines, alkaloids and antibiotics. $^{37}$

Concerning these drug effects on the ciliary body, which we explain on the basis of the prostaglandinhistamine effect, we differentiate between ciliary body oedema alone, and ciliary body oedema with an associated spastic component. It is conceivable that mild spasm of the ciliary body occurred in our first patient, who did in fact report mild pain during close work and in whom discrete cells were present in the anterior chamber. However, an unmistakable spastic component, aetiologically much more complex, was definitely present in our second patient. He suffered from aspirin-sensitive asthma caused by interference with eicosanoid metabolism. Therefore, we suspect that the ciliary body spasm was caused by a similar mechanism of action in the eye.

Despite the fact that not all the details underlying the aspirin-sensitive asthma syndrome have been elucidated, most authors agree that elevated leucotriene concentrations are spasmogenic and that the inhibition of cyclooxygenase, brought about by aspirin or other non-steroidal anti-rheumatic drugs plays a central role. ${ }^{38}$ Cyclooxygenase metabolises arachidonic acid to prostaglandins and to thromboxane $\mathrm{A}_{2}$. The alternative metabolic pathway of arachidonic acid, via the enzyme 5-lipooxygenase, leads to the formation of the leucotrienes (LT). The initial product, $\mathrm{LTA}_{4}$, is metabolised by a hydrolase to $\mathrm{LTB}_{4}$ or by glutathione- $S$-transferase to $\mathrm{LTC}_{4}$. $\mathrm{LTC}_{4}$ is then converted by gamma-glutamyl-transpeptidase to $\mathrm{LTD}_{4}$, which is ultimately transformed by a dipeptidase to $\mathrm{LTE}_{4}{ }^{39} \mathrm{LTC}_{4}, \mathrm{LTD}_{4}$ and $\mathrm{LTE}_{4}$, 
previously known as the 'slow-reacting substance of anaphylaxis', are sulphidopeptides; they are extremely potent spasmogenic agents at the level of the non-vascular, smooth musculature, including the bronchi. $^{40,41}$ Asthmatic bronchospasm can be largely explained on the basis of the spasmogenic properties of the leucotrienes. Leucotriene levels are elevated following the ingestion of cyclooxygenase-inhibiting drugs; the underlying mechanism of action is unknown. $^{42}$

At the molecular level one can imagine that, as a result of the inhibition of prostaglandin synthesis, the interactions between the prostaglandins, thromboxane $\mathrm{A}_{2}$ and the leucotrienes will be disturbed. ${ }^{43}$ These complex interrelationships are only now beginning to be explored. It has been possible to demonstrate in human neutrophils, on the one hand, that prostaglandin $\mathrm{F}_{2}$-alpha inhibits the synthesis of $\mathrm{LTB}_{4}{ }^{44}$ On the other hand, it has been shown in animal studies that the inhibition of thromboxane $\mathrm{A}_{2}$ leads to the suppression of the leucotrienes. ${ }^{45} \mathrm{We}$ believe that these interrelationships between thromboxane and the leucotrienes are disturbed in aspirinsensitive asthma. Indeed, such patients have elevated leucotriene values (urinary $\mathrm{LTE}_{4}$ ) even in the absence of stimulation with aspirin; ${ }^{42}$ their thromboxane $\mathrm{A}_{2}$ concentrations are likewise elevated. ${ }^{46}$ Following the administration of cyclooxygenase inhibitors - which cancel out the leucotriene-inhibiting effect of prostaglandin $\mathrm{F}_{2}$-alpha - a further increase in leucotriene levels takes place. ${ }^{42}$

Little is known about the intraocular effect of leucotrienes in humans apart, for example, from the fact that these substances could be detected in the aqueous humour of patients with uveitis. ${ }^{47}$ Most of our knowledge of the leucotrienes is taken from animal studies. As suggested by their name, leucotrienes $\left(\mathrm{LTB}_{4}\right)$ in animals lead to the accumulation of leucocytes, ${ }^{48}$ and to marked miosis (especially $\left.\mathrm{LTC}_{4}\right) .{ }^{49}$ However, in contrast to the prostaglandins, they do not lead to breakdown of the blood-aqueous barrier, nor do they lead to alterations in intraocular pressure. ${ }^{48,50}$

On the basis of the aspirin-sensitive asthma in our second patient, as related to the metabolic abnormalities described above, we postulate that oedema of the ciliary body was triggered in a recurrent fashion with a spastic component. We speculate that the oedema was prostaglandin/histamine-dependent, while the spasm was additionally brought on by leucotrienes. Clues supporting the hypothesis of leucotriene-induced spasm are to be found in the subjective, cramp-like pain, in the marked miosos, and in the presence of cells in the anterior chamber. We reason in this manner since pain and irritation of the anterior chamber have been described only extremely rarely in drug-induced oedema of the ciliary body.

The first clinical event in our patient with aspirinsensitive asthma occurred in the immediate postoperative phase, at a time when intraocular prostaglandin concentrations were almost certainly elevated. ${ }^{36}$ Furthermore, the active transport system of the ciliary body (responsible for the removal of prostaglandins from the intraocular fluid ${ }^{51}$ ) may have been a manifestation of a dysfunction ${ }^{52}$ due to the trauma of the operation; this would then have contributed to a further elevation in prostaglandin levels. Following the administration of the sulphonamide acetazolamide (with the resulting possible supplementary release of prostaglandins and perhaps of histamine), the equilibrium in eicosanoid metabolism was probably further upset. Compounding factors are the presumed pathological interactions among the prostaglandins, thromboxanes and leucotrienes, as well as the already elevated leucotriene levels.

The operation on the opposite eye took place without development of ciliary body oedema, in spite of the renewed administration of acetazolamide, albeit in lower doses, and not intravenously; this further refutes an allergic basis for ciliary body oedema. The pronounced manifestation of spasm of the ciliary body occurred shortly after topical application of a drop of $0.1 \%$ dipivefrine. Since adrenergic agents stimulate the synthesis of prostaglandins and of other eicosanoids, ${ }^{53}$ the resulting oedema and the spasm may be explained on the basis of the mechanisms described above. Shortly thereafter, analogous symptomatology was observed following topical treatment with pilocarpine. We explain this in the following manner: Pilocarpine occupies cholinergic muscarinic receptors. When the M2 receptor subtype is occupied mainly with guanosine-5-triphosphate (GTH)-binding protein $\mathrm{K},{ }^{54}$ the enzyme phospholipase $\mathrm{A}_{2}$ is activated. This leads to the accumulation of arachidonic acid and, ultimately, of eicosanoids. For organs such as the brain and the heart it has been possible to demonstrate that stimulation of the muscarinic receptors leads to the release of prostaglandin $E_{2}{ }^{55}$

What is unique in our patient is the chronic pain. Conceivably, the recurrent triggering of oedema of the ciliary body, accompanied by spasm, might have developed into a chronic inflammation, as is the case in aspirin-sensitive asthma.

As mentioned in the Introduction, numerous descriptions can be found of ciliary body oedema triggered by other drugs. Sulphonylurea antidiabetic drugs are related to the sulphonamides, both chemically and developmentally; therefore, a mechanism of action similar to that of the sulphonamides can be postulated. Likewise, an interrelation- 
ship with prostaglandin metabolism is recognised for aldosterone antagonists, which act at the level of the renin-angiotensin-aldosterone system. ${ }^{56}$ Analogous explanations as for aspirin-induced asthma are valid for aspirin. Promethazine, an older histamine antagonist $\left(\mathrm{H}_{1}\right.$-blocker), exerts an inhibitory influence (via G-protein) on phospholipase $A_{2}$ of the vascular endothelial cells, which synthesise mainly prostacyclin. ${ }^{57}$ Currently, we know nothing about the relationships of isotretinoin, bromocriptine and quinine with the complex metabolism of eicosanoid.

Cycloplegics are rarely successful in the treatment of oedema of the ciliary body (our first patient, and to a certain extent our second patient as well ${ }^{21}$ ); they are usually ineffective. $8,14,15,20$ They probably influence only the spastic component and lack antioedema efficacy. On the basis of our theoretical concept, it would seem plausible to consider treatment with cyclooxygenase inhibitors. However, since these drugs do not antagonise the actions of the prostaglandins but rather only inhibit their synthesis, their use in established ciliary body oedema would not seem to make much sense. In clinical situations in which a marked spastic component is present (as in our second case), it would be worth attempting therapy with leucotriene antagonists. These drugs have already proved successful in clinical trials in bronchial asthma, ${ }^{58}$ including aspirin-sensitive asthma. ${ }^{59}$ Unfortunately, this drug was not available to treat our case 2 at the time.

Since in most cases of drug-induced oedema of the ciliary body the disease is self-limiting, the difficulty lies in the diagnosis and in the withdrawal of the precipitating medication. This notwithstanding, exposure to drugs which might potentially trigger ciliary body oedema should be avoided, in particular immediately following the establishment of a correct diagnosis. Otherwise, there is a danger of chronic irritation of the ciliary body, as occurred in our second patient.

We are of the opinion that rare, drug-induced oedema of the ciliary body can be traced to a disturbance in eicosanoid metabolism. Accordingly, the oedema is mainly dependent upon the actions of the prostaglandins, while the spastic component is related rather to the leucotrienes. Numerous interfering factors combine to play a role in creating an imbalance in the complex metabolism of eicosanoids.

Key words: Aspirin-sensitive asthma, Ciliary body oedema, Drug reaction, Leucotrienes, Prostaglandins, Transient myopia.

\section{REFERENCES}

1. Ericson LA. Hygroton-induced myopia and retinal edema. Acta Ophthalmol (Copenh) 1963;41:538-43.

2. Michaelson JJ. Transient myopia due to Hygroton. Am J Ophthalmol 1962;54:1146-7.

3. Chirls AI, Norris JW. Transient myopia associated with vaginal sulfanilamide suppositories. Am J Ophthalmol 1984;98:120-1.

4. Boissonnot L, Boissonnot $\mathrm{M}$, Charles-Gervais C, Breux JP. Myopie aiguë due à lindapamide. Presse Med 1986;15:802-3.

5. Back M. Transient myopia after the use of acetazolamide (Diamox). Arch Ophthalmol 1956;55:546-7.

6. Murihead JF, Scheie HG. Transient myopia after acetazolamide. Arch Ophthalmol 1960;63:315-8.

7. Fan JT, Johnson DH, Burk RR. Transient myopia, angle-closure glaucoma and choroidal detachment after oral acetazolamide. Am J Ophthalmol 1993; 115:813-4.

8. Bovino JA, Marcus DF. The mechanism of transient myopia induced by sulfonamide therapy. Am J Ophthalmol 1982;94:99-102.

9. Teller J, Rasin M, Abraham FA. Accommodation insufficiency induced by glibenclamide. Ann Ophthalmol 1989;21:275-6.

10. Bard LA. Transient myopia associated with promethazine (Phenergane) therapy. Am J Ophthalmol 1964; 58:682-6.

11. Belci C. Myopia transitoria in caso di terapia con diuretici. Boll Ocul 1968;47:24-31.

12. Stern J. Transient myopia in a case of dermatitis treated with ACTH. Arch Ophthalmol 1956;54:762.

13. Dangel ME, Weber PA, Leier CB. Transient myopia following isosorbide dinitrate. Ann Ophthalmol 1983; 15:1156-8.

14. Manor R, Dickermann Z, Llaron Z. Myopia during bromocriptine treatment. Lancet 1981;1:102.

15. Edwards TS. Transient myopia due to tetracycline. JAMA 1963;186:69-70.

16. Michiels J, Laterre C, Dumoulin D. Les manifestations oculaires de la maladie de Wilson traitée à la penicillinamine. Bull Soc Belge Ophtalmol 1962; 132:552-61.

17. Segal A, Aisemberg A, Ducass A. Quinine, myopie transitoire et glaucome par fermeture de l'angle. Bull Soc Ophtalmol Fr 1983;83:247-9.

18. Grinbaum A, Ashkenazi I, Avni I, Blumenthal M. Transient myopia following Metronidazole treatment for Trichomonas vaginalis. JAMA 1992;267:511-2.

19. Palestine AG. Transient acute myopia resulting from isoretinoin (Accutane) therapy. Ann Ophthalmol 1984;16:660-2.

20. Sandford-Smith JH. Transient myopia after aspirin. $\mathrm{Br}$ J Ophthalmol 1974;58:698-700.

21. Beasley FJ. Transient myopia and retinal edema during hydrochlorothiazide (Hydrodiuril) therapy. Arch Ophthalmol 1961;65:212-3.

22. Maddalena M. Transient myopia associated with acute glaucoma and retinal edema. Arch Ophthalmol 1968; 80:186-8.

23. Ryan EH, Jampol LM. Drug-induced acute transient myopia with retinal folds. Retina 1986;6:220-3.

24. Solomon LM, Juhlin L, Kirschbaum MB. Prostaglandins on cutaneous vasculature. J Invest Dermatol 1968;51:280.

25. Tso MOM, Skik CY. Experimental macular edema after lens extraction. Invest Ophthalmol Vis Sci 1977; 16:381-92.

26. Ambache N. Irin, a smooth-muscle contracting substance present in rabbit iris. $J$ Physiol (Lond) 1955;129:65-6.

27. Waitzman MB, King CD. Prostaglandin influences on intraocular pressure and pupil size. Am J Physiol 1967;212:329-37.

28. Camras CB, Bito LZ, Eakins KE. Reduction of 
intraocular pressure by prostaglandins applied topically to the eyes of conscious rabbits. Invest Ophthalmol Vis Sci 1977;16:1125-34.

29. Kirchner KA, Martin CJ, Bower JD. Prostaglandin $\mathrm{E}_{2}$ but not $\mathrm{I}_{2}$ restores furosemide response in indomethacin-treated rats. Am J Physiol 1986;250:F980-5.

30. Le Bel M, Grose JH, Belleau LJ, Langlois S. Antihypertensive effects of indapamide with special emphasis on renal prostaglandin production. Cur Med Res Opin 1983;8(Suppl 3):81-6.

31. Webster J, Dollery CT, Hensby CN. Circulating prostacyclin levels may be increased by bendrofluazide in patients with essential hypertension. Clin Sci Mol Med 1980;59:125-8s.

32. O'Donnell WJ, Rosenberg M, Niven RW, Drazen JM, Israel E. Acetazolamide and furosemide attenuate asthma induced by hyperventilation of cold, dry air. Am Rev Respir Dis 1992;146:1518-23.

33. Lewis PJ, Boylan P, Friedmann LA, Hensby CN, Downing I. Prostacyclin in pregnancy. BMJ 1980; 280:1581-2.

34. Moncada S, Ferreira SH, Vane JR. Prostaglandins, aspirin-like drugs and the oedema of inflammation. Nature 1973;246:217-9.

35. Wiliams TJ, Morley J. Prostaglandins as potentiators of increased vascular permeability in inflammation. Nature 1973;246:215-7.

36. Eakins KE. Prostaglandin and non-prostaglandin mediated breakdown of the blood-aqueous barrier. Exp Eye Res 1977;Suppl:483-98.

37. Doenicke A, Schoning B. The role of histamine in adverse reactions to intravenous agents. In: Thornton JA, editor. Adverse reactions of anaesthetic drugs. Amsterdam: Elsevier/North Holland, 1981:169-238.

38. Szczeklik A, Gryglewski RJ, Czerniawska-Mysik G. Relationship of inhibition of prostaglandin biosynthesis by analgesics to asthma attacks in aspirin-sensitive patients. BMJ 1975;1:67-9.

39. Samuelsson B. Leukotrienes: mediators of immediate hypersensitivity reactions and inflammation. Science 1983;220:568-75.

40. Murphy RC, Hammarstrom S, Samuelson B. Leukotriene $C$, a slow reacting substance from murine mastocytoma cells. Proc Natl Acad Sci USA 1979;76:4275-9.

41. Morris HR, Taylor GW, Piper PJ, Tippins JR. Structure of slow-reacting substance of anaphylaxis from guinea pig lung. Nature 1980;285:104-5.

42. Christie PE, Tagari P, Ford-Hutchinson AW. Urinary $\mathrm{LTB}_{4}$ concentrations increase after aspirin challenge in aspirin-sensitive asthmatic subjects. Am Rev Respir Dis 1991;143:1025-9.

43. Lee TH. Mechanism of aspirin sensitivity. Am Rev Respir Dis 1992;145:34-6.

44. Ham EA, Sodermann DD, Zanetti ME, Dougherty HW, McCauley E, Kuehl FA. Inhibition by prosta- glandins of leukotriene $\mathrm{B}_{4}$ release from activated neutrophils. Proc Natl Acad Sci USA 1983;80:4349-59.

45. Soifer SJ, Schreiber MD, Heymann MA. Leukotriene antagonists attenuate thromboxane-inducible pulmonary hypertension. Pediatr Res 1989;26:83-7.

46. Juergens UR, Christansen SC, Stevenson DD, Zuraw $\mathrm{BL}$. Elevated thromboxane $\mathrm{B}_{2}\left(\mathrm{TXB}_{2}\right)$ and leukotriene $\mathrm{B}_{4}\left(\mathrm{LTB}_{4}\right)$ secretion from monocytes of aspirin (ASA) sensitive asthmatic patients. J Allergy Clin Immunol 1991;87:221.

47. Parker JA, Goetzl EJ, Friedlander MH. Leukotrienes in the aqueous humor of patients with uveitis. Arch Ophthalmol 1986;104:722-4.

48. Bhattacherjee P, Hammond B, Salmon JA, Eakins KE Effect of lipoxygenase products on leukocyte accumulation in the rabbit eye. Adv Prostaglandin Thromboxane Leukotriene Res 1982;9:325-30.

49. Stjernschantz J, Truman S, Sears M. Ocular responses to leukotriene $\mathrm{C}_{4}$ and $\mathrm{D}_{4}$ in the cat. Prostaglandins 1984;27:5-15.

50. Weston JH, Ableson MB. Leukotriene $\mathrm{C}_{4}$ in rabbit and human eyes. Invest Ophthalmol Vis Sci 1985; 26(Suppl):191.

51. Bito LZ, Salvador EV. Intraocular fluid dynamics. III. The site and mechanism of prostaglandin transfer across the blood-intraocular fluid barriers. Exp Eye Res 1972;14:233-41.

52. Miyake K, Shirasawa E, Hikita M. Active transport system of prostaglandins: clinical implications and considerations. J Cataract Refract Surg 1992;18:100-5.

53. Engstrom P, Dunham EW. Alpha-adrenergic stimulation of prostaglandin release from rabbit iris-ciliary body in vitro. Invest Ophthalmol Vis Sci 1982; 22:757-67.

54. Goyal RK. Muscarinic receptor subtypes: physiology and clinical implications. N Engl J Med 1989; 321:1022-9.

55. Reichmann M, Nen W, Hokin LE. Highly sensitive muscarinic receptors in the cerebellum are coupled to prostaglandin formation. Biochem Biophys Res Commun 1987;146:1256-61.

56. McGiff LC, Crowshaw K, Terragno NA, Lonigro AJ. Release of prostaglandin-like substance into renal venous blood in response to angiotensin II. Circ Res 1970;26/27:I121-30.

57. Peach MJ, Loeb AL, Singer HA, Saye J. Endotheliumderived vascular relaxing factor. Hypertension 1985;7 (Suppl I):94-100.

58. Gaddy JN, Margoleskee DJ, Bush RK, Williams VC, Busse WW. Bronchodilatation with a potent and selective leukotriene $\mathrm{D}_{4}\left(\mathrm{LTD}_{4}\right)$ receptor antagonist (MK 571) in patients with asthma. Am Rev Respir Dis 1992;146:358-63.

59. Christie PE, Smith CM, Lee TH. The potent and selective sulfidopeptide leukotriene antagonist SK \& F 104353, inhibits aspirin-induced asthma. Am Rev Respir Dis 1991;144:957-8. 